\title{
PRECOCIOUS PUBERTY WITH A REPORT ON A CASE OF PINEAL SYNDROME
}

\author{
BY \\ A. V. NEALE, M.D., M.R.C.P. \\ (From the United Hospital and Children's Hospital, Birmingham)
}

The awakening of sexual maturity is an event of considerable physiological interest, and in the light of modern knowledge of the endocrine mechanisms a profound series of hormonal reactions is known to occur. Clinical observations have gradually brought to light some of the integrating factors involved in this epochal development ; and by the careful study of aberrations from the normal, principally in cases of delayed or in accelerated puberty, it is now possible to state with some accuracy a single cause or a group of causes. It is now generally recognized that the pituitary is normally the primary directing power behind sex development, although there are most important second stations within the adrenal cortex and gonadal interstitial cells. The failure of sexual development is usually a selective or composite pituitary anterior lobe deficiency, and recent observation in pituitary cachexia has indicated the case whereby the whole endocrine basis may fail and sexual repression occur when the anterior pituitary is atrophic.

Clinicians have recognized remarkable aberrations of physical and sexual development accompanying certain types of disease within the nervous system, and in this respect the region of the midbrain and especially the immediate neighbourhood of the floor of the third ventricle is principally concerned. It would appear from a study of case records that the hypothalamic area bears some close integration in function with the pituitary gland in regard to both lobes.

Cloake (1927) reports a detailed study of the anatomy of the hypothalamic area, and he notes the vast number of small cells of unknown functions in the tuber and the fact that the pituitary gland receives nerve fibres from this region. Experimental evidence is extensively surveyed and no doubt is placed upon the vital functions of the tuber and neighbouring nuclei in their physiological rôle in carbohydrate, water, and body weight regulation. Collateral function with the pituitary and the sympathetic mechanisms is adduced and even psychic changes have been observed in syndromes of tuberal origin. This author sums up his views, after a most careful anatomical, physiological and clinical survey - the posterior lobe is but a displaced part of the tuber, and its displacement so far back in the scale of evolution would seem to point to a close functional relation between it and the anterior lobe and pars intermedia and with the region of the brain whence it was derived.' 
Disorders, especially polyuria and obesity, referable to posterior lobe dysfunction following inflammatory disease in midbrain centres are discussed in detail by Eaves (1930). Walsh (1926) observed a general tendency to change in physical stature after mesencephalic encephalitis. Similar phenomena are occasionally seen after prolonged chorea.

An interesting clinical story is related by Stewart (1938). A male child, aged three, acquired obesity, which was followed later by polyuria, polydipsia, excessive somnolence and finally hyperglycaemia. Microscopically gliosis and chronic degenerative changes were found in nerve cells of the hypothalamic nuclei.

Schlesinger (1934) records the case of a girl aged eight-and-a-half years, who developed precocious sexual appearances following postbasic meningitis with internal hydrocephalus. Ford and Guild (1937) review precocious puberty in the light of nervous disease and record two cases of premature sexual development in young girls after measles-encephalitis and in one boy after encephalitis lethargica.

Neoplastic processes arising in the hypothalamic tissue have been associated with the development of considerable sexual precocity. An example is recorded by Heuyer (1931) in a boy aged six years. Macrogenitosomia and advanced secondary sexual character developed. Pathological investigation later revealed an ependymoglioma in the region of the infundibulo-mammillary zone, strictly limited in nature and without any destructive effects upon the hypothalamic centres. Dods (1934) observed a boy aged three years to be precociously developed and by the age of eight years showed the sexual characteristics of late adolescence. An astrocytoma of the floor of the third ventricle was present. Probably the most remarkable example recorded to date concerning this group syndrome is that of Marchard and Russell (1935). In this case pubertas praecox was associated with a tumour of the floor of the third ventricle. At the age of two years considerable sexual excitement and at times almost maniacal activity was observed. His mental and physical development was amazingly precocious, and the authors acted heroically in an attempt to stem the rush of his sexual behaviour. One testicle and later one suprarenal gland were removed without any improvement. There were no neurological physical signs indicative of an intracranial lesion, but in retrospect the authors regard the facts of subnormal temperature, extreme variations in behaviour and restlessness to be of localizing value and might have directed suspicion upon the subthalamic areas. The exaggerated activity and abnormal sexual behaviour seen in this case were similar to those seen in some cases of post-encephalitic psychosis. It should be mentioned, in contrast, that the central characters in this case were rather contrary to the more usual reserved and quiet character of many children with precocious puberty. Reserve, possibly due to a degree of selfconsciousness, is rather a feature of macrogenitosomia. This boy died of acute rheumatic carditis at the age of four-and-a-half years. Necropsy revealed no detectable intrinsic endocrine abnormality. The pituitary and the pineal glands were normal. A circumscribed tumour was found attached to the right corpus mammillare and to the left side of the tuber cinereum. There was no hydrocephalus and no obvious disturbance of the adjacent hypothalamus, apart from slight pocketing of the floor of the third ventricle where the tumour was attached. In a general review these authors advance the hypothesis that in cases in which the pineal, the adrenal, the gonads, or the hypothalamus are involved, pubertas praecox may occur by an influence on the hypothalamic centres and from these on the pituitary.

It is a remarkable fact that in no case of sexual precocity has a tumour or a directly responsible lesion in the pituitary gland been detected (Lisser). This is 
in contrast with the interesting clinical appearances brought about in hyperplastic or neoplastic changes in other endocrine glands. The suprarenal cortex, especially when tumour formation is present, leads to masculinization, heavy somatic development and sexual precocity. Brilliant results are therapeutically possible in such patients, as for instance in Lisser's case of an adrenal cortical adenoma removed by operation in a boy aged five years, who had remarkable sexual virilism, but was freed from this by the surgical success. Masculinizing influences are seen in the more rarely occurring ovarian arrhenoblastomas. Precocious puberty and menstruation, but not necessarily ovulation, is a rare occurrence in girls, but examples of this disturbance are now amply recorded, and the significantly associated granulosa cell ovarian tumour has become an established clinical entity. By analogy the true interstitial-cell tumour of the testicle, inducing early sex development, is recognized and a typical case is recorded by Sutherland (1932).

The pineal gland would seem to be a physiologically inactive body. Experimental investigation has yielded negative results. Quite recently a further amount of work has been done on pineal tissue, a large amount of which has been available; detailed examination has so far failed to demonstrate any hormonal activity on mammals (Med. Res. Council Report, 1936-1937). Information to date seems to indicate that the pineal body plays no significant rôle in the production of macrogenitosomia praecox, the gland having been found to be normal in many cases of the fully-developed syndrome, and destruction of the pineal has not led to any apparent change in the genital organs. There is no instance where a verified true pinealoma has been found in macrogenitosomia praecox (Ford and Guild). However, a tumour of the pineal area and of the hypothalamus may produce a similar syndrome.

Gardiner-Hill (1937) reviews the general situation and observes that the 'pineal' tumours found in cases of macrogenitosomia praecox have only one feature in common-that they arise in the general region of the pineal. It would appear that the pineal played no intrinsic significant part in the production of the general body changes and that the syndrome is probably due to a direct or indirect destructive process in the walls of the third ventricle. Gardiner-Hill regards the clinical picture, apart from the neurological signs, as quite similar to that of macrogenitosomia praecox due to interstitial-celled testicular tumour. Confusion and difficulty surround possible explanations why a tumour in the pineal zone may produce signs of sexual precocity, and it must remain for the present a simple clinical fact that male children only are affected in this way.

Kinnier-Wilson (1925) observed that pubertas praecox was more often not seen than seen in these tumours, and he questioned how much was due to neighbourhood disturbances. It would appear that occasionally a 'pineal' tumour may be associated with sexual involution, as is reported by Cleghorn (1938) of a male aged twenty-three years, who had a tumour ('pinealoma') causing internal hydrocephalus, hypogonadism and some evidence of other endocrine insufficiency. He proposed that the condition had been brought about by neuropituitary disturbance, there being, however, no histological abnormality in the pituitary gland.

The first review of pineal tumours was made by Horrax and Bailey (1925). They regard the pineal gland to be composed of two categories of cells : $(a)$ 
parenchymatous and questionably glandular, (b) neurological; and that neoplasia may involve either cell type, but no correlation with sex-stimulating effect could be ascribed to either. Of twelve verified cases five occurred before puberty and seven in adults. The girls affected showed no sexual precocity. Haldeman (1927), in a survey of 113 cases of pineal tumour, found that fiftythree had occurred in persons under twenty years of age, and of these forty-five were males and eight females. In the male cases sixteen, all between the ages of three years and twelve years, showed macrogenitosomia praecox, and in ten the pathology of the tumours was histologically teratomatous.

Owing to the anatomical locality of the pineal tumour it is clear that the neurological effects chiefly concern the oculomotor apparatus, the inferior corpora quadrigemina, the cerebellum and cerebellar peduncles, with superimposed signs due to intracranial pressure, and internal hydrocephalus. Horrax (1925) states 'in the presence of an intracranial pressure syndrome which simulates a cerebellar lesion, if there be added to the picture an involvement of one or both trochlear nerves, together with recurring changes in the size of one or both pupils and a tendency to spasticity in the lower limbs, a tumour of the pineal body should be suspected.'

Kinnier-Wilson observed that tumours in the antero-posterior axis of the brain tend to cause falling in backwards or forwards directions, and that pineal tumours had a special tendency to set back upon the superior corpora quadrigemina and be associated with loss of up-and-down movements of the eyes. Haldeman, in his large series of cases, found significant localizing signs to be paralysis of upward eye movements, diplopia, trochlear palsy, ptosis, nystagmus, and occasionally absence of the light reflex of the pupil.

Within the clinical experience of any individual physician or even in that of a large hospital, the occasion for recognition of the pineal syndrome with pubertas praecox must be very uncommon ; yet the clinical picture is so remarkable and characteristic, and, as the present case shows, remedial therapy may prove so promising and dramatic in effect, that the writer considers it of importance that clinicians should recognize the disorder and institute as early as possible therapeutic measures, principally to check the papilloedema and to minimize the precocious sexual changes.

\section{Case Report}

Eric K, aged nine years, was the first child of three. The boy seemed perfectly well until August, 1936, when he began to vomit. This, in the early stages of the illness, usually occurred early in the morning; but as time went on he vomited several times a day. It was some months later (December, 1936) that he developed frontal headache. Each attack was severe and lasted about thirty minutes. During the following two months a gradual impairment of his sight took place, this being first recognized at school owing to his increasing difficulty in seeing the blackboard. He developed secondary sexual characters during the six months before coming under medical observation in March, 1937. The boy had not shown any mental changes or sexual advancement and his parents were not particularly concerned about him beyond the troublesome vomiting.

Clinical examination showed him to be a big, well-developed child with 
strong muscles, heavy and bushy eyebrows, hair on the upper lip, abundant pubic hair, and the external genitals were of adult type. The testicles appeared normal, but proportionately enlarged. Thoracic and abdominal examinations were negative. No suprarenal gland abnormality was detectable; thyroid gland was normal. Heart and blood vessels were normal. Blood pressure was $12070 \mathrm{~mm}$. Hg. Urine and blood were normal. Ophthalmoscopic examina-

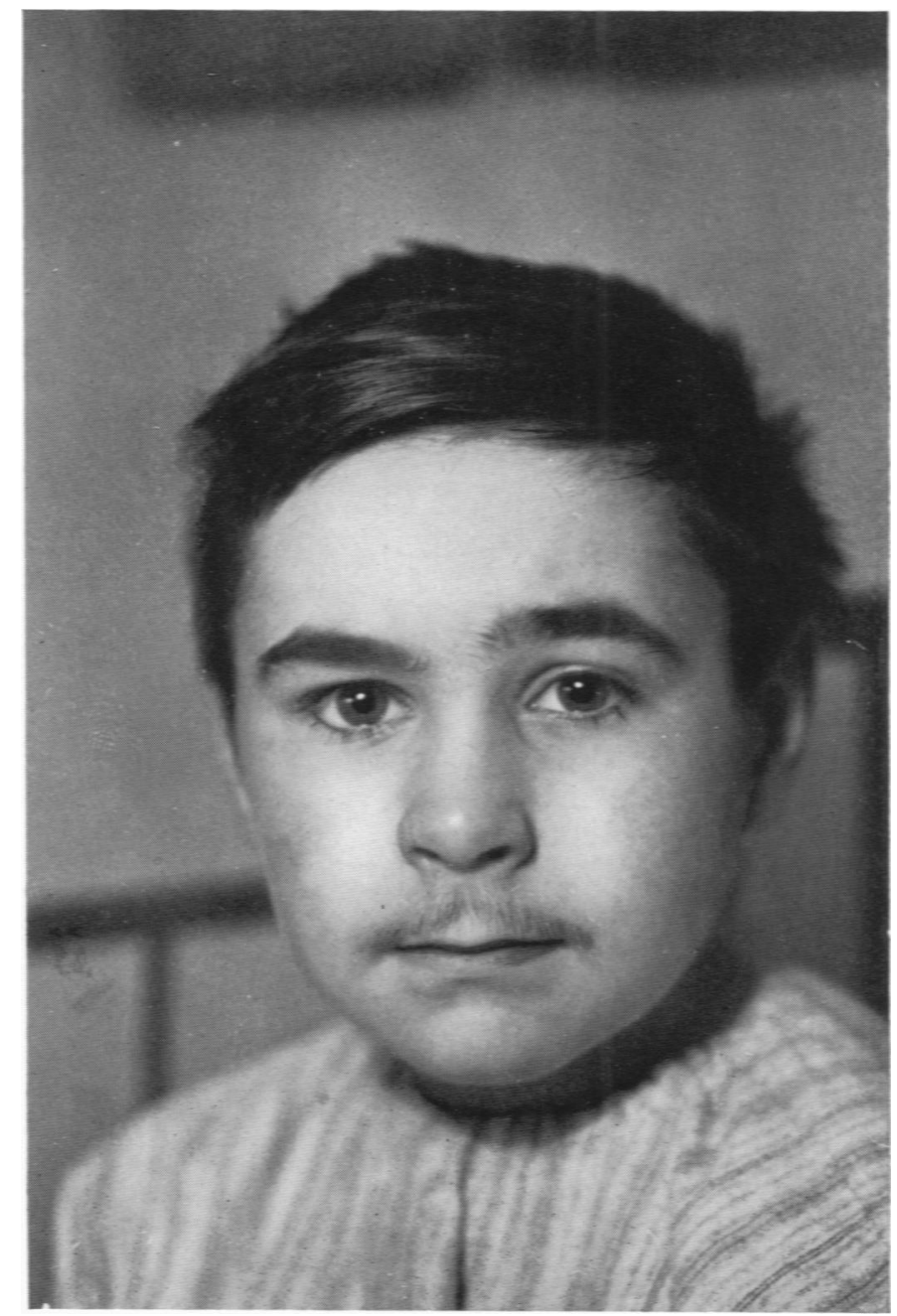

Fig. 1.-Eric K.

tion revealed bilateral and severe papilloedema. There was slight spasticity of the lower limbs. The left plantar reflex was extensor. Right plantar reflex was variable. There was nystagmus chiefly on left deviation and slight on right deviation. Ocular movements were full. There was no loss of vertical movement of the eyes. The pupil reactions were normal. The visual fields showed general contraction and did not suggest direct pressure in the visual pathways, but some general and indirect pressure, possibly by enlargement of the third ventricle (Dr. P. Jameson Evans). The cerebro-spinal fluid was clear and 
normal. Ventriculography (Mr. Stammers) showed that the lateral ventricles and the third ventricle were enlarged. The ventricular system filled with air as far as the aqueduct of Sylvius. A block was present at this level and no air filling occurred in the fourth ventricle. This evidence confirmed the localization of the tumour to be at or near the pineal zone.

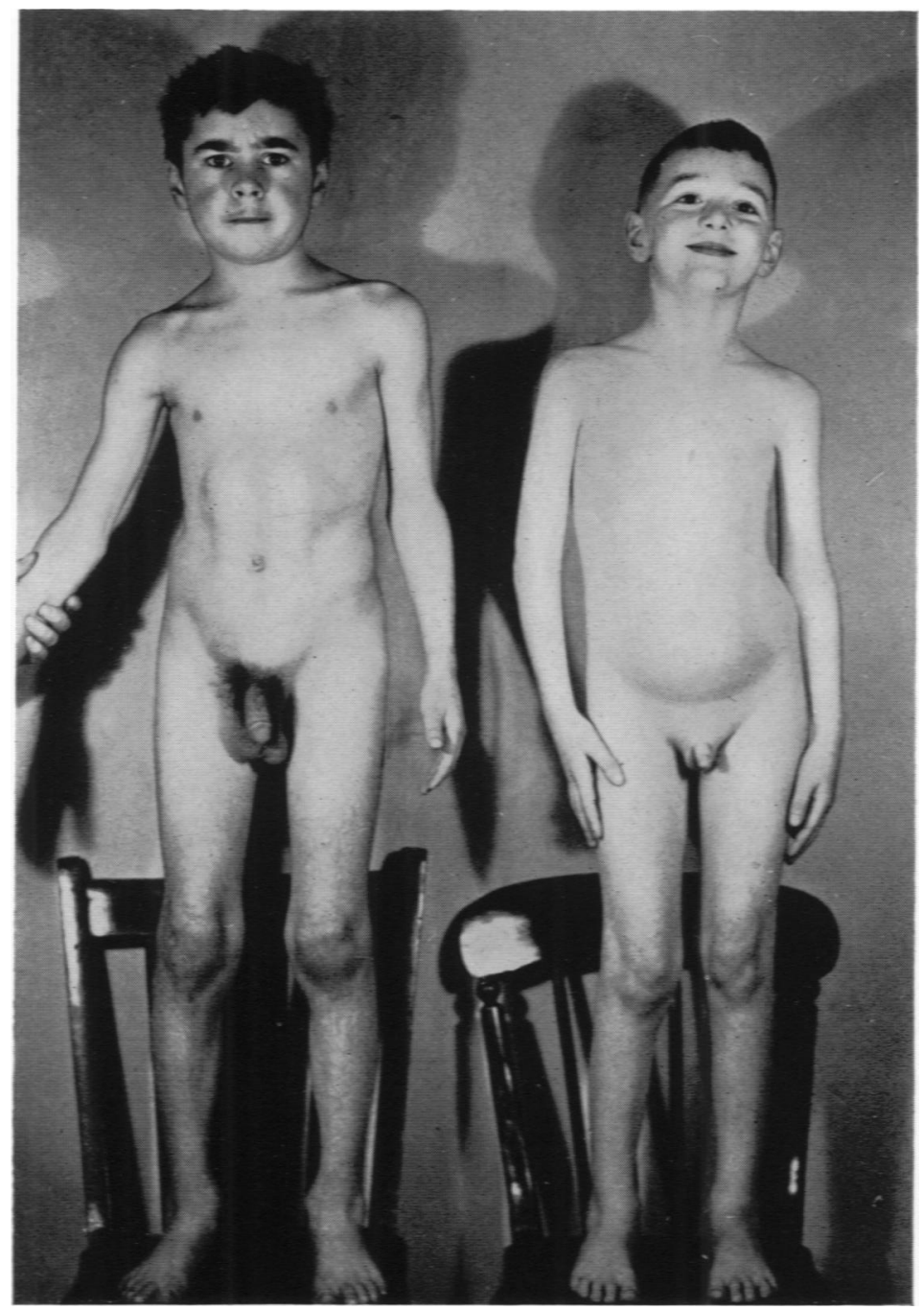

Fig. 2.-Eric $K$ and a boy of the same age.

TreatMent.- In consultation with Mr. Stammers it was decided that direct exploration of the tumour was highly dangerous, and therefore deep $x$-ray treatment was decided upon. A right temporal decompression was carried out as a preliminary measure. Fourteen days later deep $\mathrm{X}$-ray therapy was commenced by Dr. Bromley at the General Hospital. This therapy consisted of twenty-one treatments to three fields $-2,100 \mathrm{~V}$. units to skin by each field and $2,900 \mathrm{~V}$. units to the tumour. This treatment was concluded in July, 1937. During the treatment there was a variable degree of intracranial pressure, as 
judged by the tension in the decompression area, and on several occasions considerable increase was evident and associated with severe vomiting ; but these symptoms were controlled by intravenous hypertonic glucose solution. In a few weeks remarkable improvement was evident, the neurological signs had disappeared, vision improved, and there was a marked decrease in papilloedema.

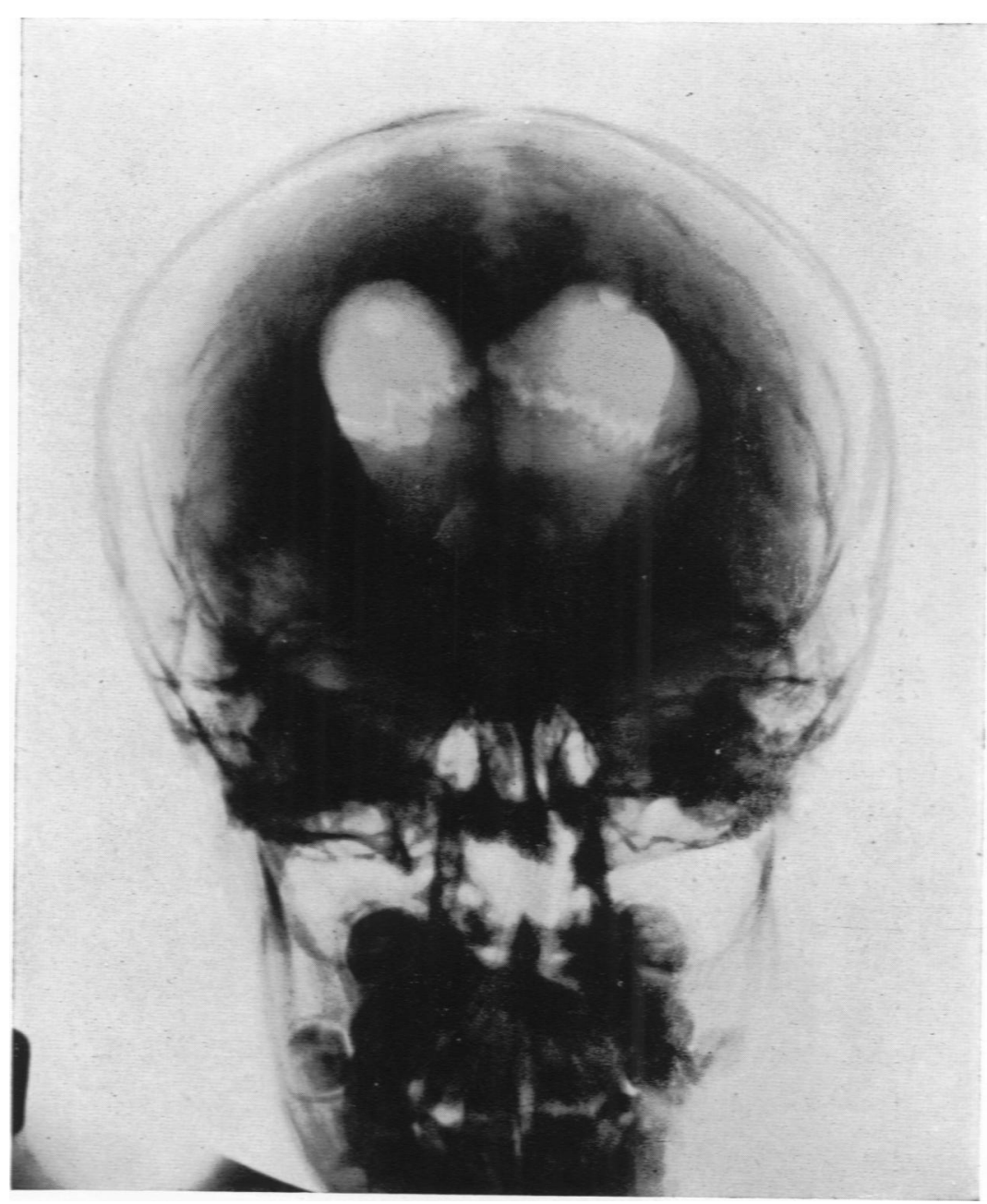

FIG. 3.-Ventriculogram showing dilated ventricles.

In November his condition was satisfactory, but there was no appreciable change in the sexual organs. In May, 1938, his height was 4 feet 9 inches and he weighed seven stone ; he had good vision, the visual fields were practically full and the fundi clear. He had returned to school.

The causation of sexual precocity in 'pineal' tumours remains a physiological mystery, but the puzzle may be solved when the functions of the midbrain are better understood and more information on neuro-endocrine linkage is available. 
In this case, which is the only example in which deep x-ray treatment is recorded, therapeutic success has occurred beyond expectation.

Thanks are due to Dr. Teall and to Dr. Thorpe for the radiographic examinations.

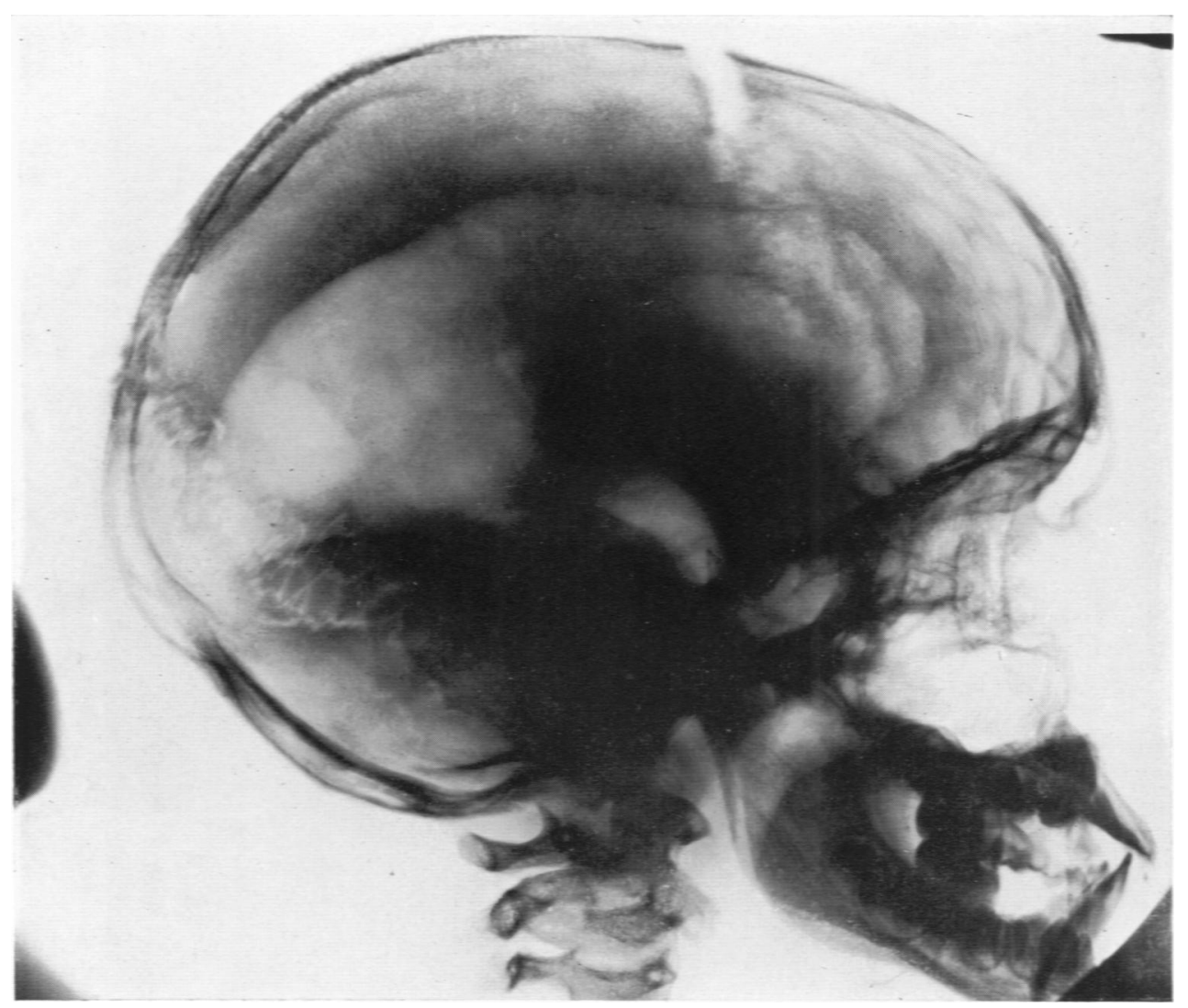

FIG. 4.-Ventriculogram showing obstruction at the aqueduct of Sylvius.

\section{REFERENCES}

Cleghorn, R. A., et al. (1938). Quart. J. Med., 7, 183.

Cloake, P. C. (1927). Proc. roy. Soc. Med., 20, 1,643.

Dods, L. (1934). Med. J. Austral., 2, 277.

Eaves, E. C. (1930). Brain, 53, 56.

Ford, F. R., and Guild, H. (1937). Johns Hopk. Hosp. Bull., 60, 192.

Gardiner-Hill, H. (1937). Brit. med. J., 1,247.

Haldeman, K. O. (1927). Arch. Neurol. Psychiat., 10, 724.

Horrax, G., and Bailey, P. (1925). Arch. Neurol. Psychiat., 13, 423.

Huyer, G., et al. (1931). Rev. Neurol., 2, 194.

Kinnier-Wilson, S. A. (1925). Arch. Neurol. Psychiat., 13, 423.

Le Marquand, H. S., and Russell, D. S. (1934-35). Royal Berks. Hosp. Rep., 31.

Lisser, H. (1933). Trans. Assoc. Amer. Phys., 8, 225.

Schlesinger, B. (1934). Proc. roy. Soc. Med., 29, 149.

Stewart, R. M. (1938). J. Neurol. Psychiat., 1, 68.

Sutherland, D. M. (1932). Brit. J. Surg., 20, 343.

Walsh, T. G. (1926). J. Amer. med. Ass., 87, 305. 